\title{
Interações do ambiente judiciário e famílias pobres: risco ou proteção às relações familiares?
}

Interactions between the judicial environment and poor families: risk or protection of family relations?

Interacciones del ambiente judiciario y familias pobres: ¿riesgo o protección a las relaciones familiares?

\author{
Simone de Biazzi Avila Batista Silveira* \\ Maria Angela Mattar Yunes
}

\begin{abstract}
Resumo
A qualidade das relações familiares tem expressivo papel na existência humana e contribui para aprimorar estruturas sociais. A abordagem bioecológica de desenvolvimento humano destaca a importância dessas e de outras interações. Este estudo visou a investigar os processos relacionais que operam no atendimento oferecido pelo ambiente judiciário às famílias pobres em conflito judicial. $\mathrm{O}$ método utilizado foi a inserção ecológica, e os instrumentos de coleta de dados foram o diário de campo e a entrevista semiestruturada com operadores do Direito e uma família litigante na Justiça. Os resultados apontaram para um sistema de crenças específico dos profissionais, percepção distorcida das famílias sobre o Judiciário e a ausência de entendimento entre os envolvidos no decurso do processo. A desconexão entre os profissionais que representam o Judiciário e as pessoas envolvidas nos conflitos judiciais familiares parece apontar para riscos às relações familiares em vez da preconizada proteção instituída na Constituição Federal.
\end{abstract}

Palavras-chave: relações familiares; famílias pobres; ambiente judiciário.

\section{Abstract}

The quality of family relations plays a significant role in human existence and contributes to the improvement of social structures. The bioecological approach to human development highlights the importance

\footnotetext{
Texto recebido em dezembro de 2009 e aprovado para publicação em abril de 2010.

Mestra em Educação Ambiental pela Universidade Federal do Rio Grande (FURG), professora assistente da Faculdade de Direito da Universidade Federal do Rio Grande.E-mail: simonebiazzi@vetorial.net.

* Doutora em Educação pela Pontifícia Universidade Católica de São Paulo, professora assistente do Instituto de Ciências Humanas e da Informação da Universidade Federal do Rio Grande (FURG). E-mail: mamyunes@yahoo.com.br.
} 
of those and other interactions. This study aims to investigate relational processes operating in the attendance offered by the judiciary environment to poor families in judicial conflicts. The ecological engagement method was employed. The data collection instruments were field diary and semistructured interviews with law workers and a family in judicial conflict. Results indicated a belief system concerning the professionals, the families' distorted perception of the judicial system, and the absence of understanding between those involved in the process. The disconnection between professionals representing the judicial system and people in judicial conflicts seems to point out risks to family relations instead of the alleged protection established by the Federal Constitution. (148)

Key-words: family relations; poor families; judicial environment.

\section{Resumen}

La calidad de las relaciones familiares tiene expresiva función en la existencia humana y contribuye para perfeccionar estructuras sociales. El abordaje bioecológico del desarrollo humano destaca la importancia de éstas y otras interacciones. Este estudio pretende investigar los procesos relacionales que actúan en la atención ofrecida por el ambiente judiciario a las familias pobres en conflicto judicial. El método utilizado fue la inserción ecológica, y los instrumentos de la colecta de datos fueron el diario de campo y la entrevista semi-estructurada con ejecutores de Derecho y una familia litigante en la justicia. Los resultados apuntaron para un sistema de creencias específico de los profesionales, percepción destorcida de las familias sobre el judiciario y la ausencia de entendimiento entre los afectados en el decurso del proceso. La desconexión entre los profesionales que representan el judiciario y las personas envueltas en los conflictos judiciales familiares parece apuntar para riesgos a las relaciones familiares al contrario de la preconizada protección instituida en la Constitución Federal.

Palabras claves: relaciones familiares, familias pobres, ambiente judicial.

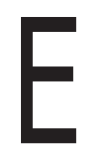

studiosos de vários campos de conhecimento apontam a família como um dos mais importantes contextos de desenvolvimento humano. Esse reconhecimento reitera a importância de estudos que focalizem os mais variados aspectos desta histórica e humana instituição relacional. O presente texto é recorte de um estudo que teve como principal objetivo compreender como são processados os conflitos familiares no âmbito dos ambientes e espaços judiciais. Entre os vários aspectos que compõe o referido trabalho, a visão dos profissionais que atuam no ambiente judiciário sobre 
as famílias atendidas (em especial sobre as famílias pobres) foi foco deste estudo. Alguns elementos de destaque foram as influências que as crenças dos profissionais exercem sobre a condução das lides processuais. Assim, partindo de uma análise da família como contexto de desenvolvimento humano e passando pela concepção jurídica da família, o artigo adentra os objetos de pesquisa propriamente ditos, tais quais apresentar os dados obtidos sobre as concepções de família para os operadores jurídicos e as influências dessas visões na condução dos conflitos judicializados em casos de famílias pobres que fazem uso de um serviço gratuito.

\section{A família como contexto de desenvolvimento humano em situação de pobreza}

Ao longo da história, não há sociedade que tenha vivido à margem de alguma forma de instituição familiar ou de alguma forma de institucionalização das relações entre seus membros. No entanto, há autores que remarcam que "a família não é algo biológico, algo natural ou dado, mas produto de diferentes formas históricas de organização entre os humanos que, aos poucos, foram sendo institucionalizadas na forma de organizaçoos familiares" (Narvaz, 2005, p. 25). Outros pensadores trazem a ideia de que a família da atualidade é uma invenção moderna, que deixou de ser apenas uma instituição de direito privado para a transmissão do nome e dos bens, para assumir uma função moral e espiritual, "passando a formar os corpos e as almas" (Ariés, 1981, p. 277).

É importante dizer que o conceito de família é polissêmico. No sentido mais restrito, refere-se ao núcleo familiar básico. Num sentido mais amplo, é o grupo de indivíduos vinculados entre si por laços consanguíneos, consensuais ou jurídicos. Assim, constituem-se complexas redes de parentesco que são atualizadas por meio de trocas, cooperação e solidariedade. Os limites variam de acordo com cultura, região e classe social (Salles, 1999; 2002; Tuirán, 2002). Carvalho \& Almeida (2003) afirma que "A família é apontada como elemento-chave não apenas para a 'sobrevivência' dos indivíduos, mas também para a proteção e a socialização de seus componentes, transmissão do capital cultural, do capital econômico e da propriedade do grupo, bem como das relações de gênero e de solidariedade entre gerações" (Carvalho \& Almeida, 2003, p. 109).

A família é, portanto, um contexto de desenvolvimento humano, no qual se processam interaçôes significativas entre pessoas (Bronfrenbrenner, 1996; Rodrigo \& Palacios, 1998). Assim, estimular o desenvolvimento saudável das relaçôes familiares significa promover o desenvolvimento positivo dos seres 
humanos integrantes dessas famílias, bem como relevar sua tarefa socializadora. Segundo Gomes (1992), "Ela faz a primeira inserção da criança no mundo social objetivo, à medida que promove a aprendizagem de elementos culturais mínimos: linguagem, hábitos, usos, costumes, papéis, valores, padrões de comportamento e de atitudes, etc." (Gomes, 1992, p. 96).

Rodrigo e Palácios (1998) apontam que a família é um cenário de construção de pessoas adultas, de autoestima e bem-estar psicológico. É um lugar onde se aprende a enfrentar desafios e assumir responsabilidades e compromissos. Representa, outrossim, para os autores mencionados, não apenas um contexto de desenvolvimento e realização pessoal dos adultos, mas é cenário de encontro intergeracional. Além de formar uma rede de apoio social para os filhos, a família tem a função de assegurar a sobrevivência deles, seu crescimento, socialização e proporcionar um clima de afeto que possibilite estímulos para os seus relacionamentos com o ambiente físico e social. A função educacional da família se destaca. A educação é um espaço de descobertas e de invenção de novos gestos, de novas açôes. Para Valadares (1999), "A família foi um lugar inicial de educação e, seja qual for a família, de forma melhor ou pior, ela acolhe e sustenta, ensina continuidades e cortes próprios da vitalidade" (Valadares, 1999, p. 26).

Os aspectos aqui abordados têm especial importância quando se fala das famílias pobres, pois muitas crenças a respeito da pobreza se alimentam da raiz da patologia social, que ameaça os projetos de vida e de ascensão social das classes médias. De acordo com Mello (1995), a família pobre é quase sempre declarada incompetente. A autora reitera: "Seus membros adultos são desqualificados culturalmente. Suas funções essenciais de socialização são responsáveis pela geração de 'personalidades deformadas', ou seja, inaceitáveis, capazes de cometer as mais bárbaras atrocidades” (Mello, 1995, p. 52). Assim, a representação da família, embora compreensível para o senso comum, não é e nem poderia ser idêntica. É preciso saber de qual família estamos falando, em que contexto ela está inserida, situá-la no tempo e identificar os processos pelos quais passou ou está passando, e isso vale também quando falamos de famílias pobres.

$\mathrm{O}$ avanço no enfrentamento da questão da pobreza mostra que as pessoas não deixam de trabalhar por vontade própria: o sistema produtivo é que é incapaz de absorver a população (Valadares, 1991). Tais considerações precisam ser feitas e refeitas, pensadas e repensadas, sob pena de não somente culpar as famílias por sua condição de pobreza, mas, sobretudo de não se fornecer a elas a estrutura social adequada ao seu desenvolvimento. Isso nos conduz a dar especial atenção aos estudos sobre a importância da situação 
familiar dos pobres e o seu desenvolvimento psicossocial. Segundo Rosemberg (1994), o cuidado no estudo com famílias pobres deve ser acurado no sentido de que, ao orientar o discurso a respeito delas, não se redunde em processos de estigmatização. De acordo com a autora, a ênfase reducionista de grande parte das ações previstas para famílias pobres gira em torno de dois eixos principais, a saber:

1. O subdesenvolvimento é homogeneamente idêntico através dos continentes e dentro de um mesmo continente. A América Latina é homogênea e seus pobres são iguais.

2. Nesse contexto de pobreza, as famílias pobres praticam excessos que colocam em risco sua prole. Nas famílias pobres, as mulheres são vistas, antes de tudo, como reprodutoras descontroladas, que causam a perpetuação da pobreza e colocam em risco a ecologia global (Rosemberg, 2004, p. 29).

Essas crenças são reforçadas diariamente, seja pelas políticas que excluem, ao invés de incluir, seja pela maneira como os problemas sociais são enfrentados, principalmente, pela mídia, que tem o poder de fazer crer naquilo que faz ver e ouvir. Rosemberg (1994) completa seu raciocínio, manifestando sua preocupação de que o imaginário que informa tais imagens da pobreza de famílias seja estigmatizante e reforce os processos de exclusão social, por meio de políticas públicas excludentes. $\mathrm{O}$ adjetivo estigmatizante pode ser mais bem compreendido com base no conceito de estigma (Gofmann, 1988) e é definido como uma atribuição social de desvio, incorporada numa identidade deteriorada atribuída a uma pessoa numa relação que implica desvalorização. O estigma é empregado para produzir e reproduzir relações e desigualdades sociais legitimadas por saberes técnicos. As crenças, assim, transformam diferenças em desigualdades de classe, de gênero, de idade, de raça ou etnia, de sexualidade ou orientação sexual. O estigma tem sido empregado para dar legitimidade ao status dominante dentro de estruturas de desigualdade social existentes.

Alguns autores (Carvalho \& Guará, 1994; Draibe, 1994), quando se reportam à pauperização de enorme contingente da população brasileira, recomendam que a reforma das políticas e dos programas sociais coloquem a família como eixo e prioridade das açóes governamentais nesse campo, propondo, para além do combate a pobreza e exclusão social, a realização de programas de geração ou complementação de emprego e renda e de uma rede de serviços comunitários. Em sociedades como o Brasil, onde não se dispõe de um sistema de políticas sociais mais efetivo e abrangente, as 
condições de subsistência das famílias são determinadas por seu nível de rendimentos (Carvalho \& Almeida, 2003). Por isso mesmo, as mudanças e os fenômenos assinalados vêm tendo claros e fortes impactos sobre a organização e as condições de vida das famílias brasileiras, e afetam negativamente sua capacidade de atender às necessidades básicas de seus membros e propiciar-lhes efetiva proteção social.

O estudo de Carvalho \& Almeida (2003), aponta pesquisas (Salles, 2002; Oliveira \& Ariza, 2002; Goldani, 2002; Montali, 2000) que têm ressaltado como essas questões afetam também os padrões de organização do grupo familiar. A pesquisadora aponta que, nas classes populares, o homem ainda é considerado e valorizado como chefe e provedor da família, enquanto que as mulheres acabam percebendo o casamento como apoio moral e econômico e, muitas vezes, como uma oportunidade de parar de trabalhar, dedicando-se aos afazeres domésticos e à criação dos filhos. Ocorre que, com os altos índices de desemprego e os baixos níveis de remuneração, surge a inviabilidade dessa divisão sexual de responsabilidades, e o projeto feminino de melhorar de vida pelo casamento é frustrado, enquanto o homem, impossibilitado de cumprir o seu papel, fracassado, envereda-se, muitas vezes, pelo alcoolismo ou abandona a família.

Atingida pelas mudanças assinaladas e por processos sobre os quais não tem controle, a família vem perdendo gradativamente sua capacidade de funcionar como amortecedor da crise e como mecanismo de proteção de seus componentes. A ruptura das possibilidades objetivas de manter o padrão de família culturalmente estabelecido e dominante pode implicar no aumento dos conflitos e parece estar contribuindo para o aumento das separações e das famílias monoparentais, chefiadas sobretudo por mulheres (Garcia \& Yunes, 2006). Diversos estudos têm analisado como, na história brasileira, os desafios de combate ao pauperismo e de regulação e controle das desigualdades e das injustiças nunca foram priorizados e efetivamente enfrentados (Carvalho, 2001; Mello, 1995; Sarti, 1996; Szymanski, 2004). Some-se a tudo isso o fato de que os profissionais sociais que trabalham com essas famílias nos programas de intervenção, principalmente governamentais, têm a sua prática coordenada por crenças nada otimistas em relação ao público-alvo.

Com efeito, investigaçôes realizadas em diferentes categorias de trabalhadores sociais brasileiros (Yunes, Miranda \& Cuello, 2004; Yunes, 2001) revelaram que suas práticas profissionais com famílias de baixa renda são pautadas por teorias implícitas pessimistas explicadas como "desestrutura", "acomodação", "carência”, "violência” e "drogadição". Foi 
constatado que tais elementos sublinham apenas as impossibilidades dos grupos pobres e têm considerável impacto no atendimento e nas interaçôes profissionais-famílias. Os resultados evidenciaram posturas "paralisadas" ou ações assistencialistas que podem comprometer a autonomia e o desenvolvimento humano das populações atendidas. Tais concepções são importantes para serem observadas e debatidas incansavelmente, vez que, se absorvidas sem crítica ou reação, servem de fundamento, justificativas ou argumentos para a perpetuação de "políticas especiais para a pobreza”. Importante ressaltar, no entanto, que tais políticas, longe de servirem como proteção às famílias, apresentam-se como políticas sociais preventivas e de emergência, em detrimento às políticas sociais para todos como reconhecimento da cidadania. Para a disposição de políticas sérias de proteção à família, é preciso ressignificá-la com base em novas atitudes em relação a ela, superando condutas que, para Carvalho e Guará (1994, p. 48), são "pautadas na visão de família como incapaz, incompetente, desestruturada ou culpada”.

\section{A família e o Direito}

A evolução legislativa no Brasil apresenta uma mudança bastante significativa nos últimos anos. Com efeito, o Código Civil de 1916 regulava a família do início do século passado, constituída unicamente pelo matrimônio: impedia a dissolução, fazia distinções entre seus membros e trazia qualificações discriminatórias às pessoas unidas sem casamento e aos filhos dessas relações. As referências feitas aos vínculos extramatrimoniais e aos filhos ilegítimos eram punitivas e tinham por finalidade a exclusão de direitos. Corroborando com esse conceito, na Constituição de 1946, família era "constituída pelo casamento de vínculo indissolúvel e terá direito à proteção do Estado" ${ }^{1}$, dispositivo que foi repetido na Constituição Federal de 1967. Até o advento da Constituição de 1988, a família somente seria juridicamente reconhecida por meio do casamento civil. Naquela época, validar qualquer outro tipo de união diversa do casamento civil era tarefa bastante árdua. Sucessivas alterações legislativas buscavam adequar a lei às situações fáticas que passaram a aparecer com maior frequência, regulando, dessa forma, os direitos dos cônjuges, eliminando a ideia da família como instituição sacralizada. Hoje, o conceito constitucional de família é bem mais amplo e acabou por definir que "a família, base da sociedade, tem especial proteção do Estado", acrescentando que "para efeito de proteção 
do Estado, é reconhecida a união estável entre o homem e a mulher como entidade familiar, devendo a lei facilitar sua conversão em casamento". ${ }^{2}$

No entanto, a abertura necessária para a análise do contexto familiar é pouca ou nenhuma no âmbito legal, já que, em grande parte, a doutrina jurídica contempla com a expressão "desorganização familiar" a causa da atual "crise profunda” (Cahaly, 2000) pela qual passa a instituição. Embora para alguns juristas, essa "crise" seja mais aparente do que real, é bem verdade que, assim mesmo, continuam usando o termo para designar o que pode perfeitamente ser entendido como polimorfismo familiar. A doutrina jurídica é firme em apontar que houve uma mutação de conceitos básicos, e, por conseguinte, "o enfraquecimento gradativo da disciplina familiar e a desconsideração paulatina do significado do vínculo matrimonial, pelo relaxamento dos costumes, pelas liberdades e concessões de toda ordem como justificativa do descarte de preconceitos tradicionais" (Cahaly, 2000, p. 19).

O modelo de família idealizado no imaginário social da contemporaneidade, que é o da "família nuclear burguesa com conotação normativa" (Szymanski, 1995, p. 26), é visto como a situação ideal dentro da conceituação jurídica, sendo considerada "desorganizada" a família que foge ao padrão de composição mãe, pai e filhos. Importante ressaltar que essa parece ser a crença que vigora ainda nas varas judiciais especializadas em direito de família, onde as "partes" são recebidas sempre com reserva, já que "não conseguiram" evitar o conflito ou não optaram por resolvê-los dentro do "âmbito familiar". Nesse sentido, as famílias, principalmente as pobres, já são recebidas sob a égide da “incompetência”. Rosemberg (1994) afirma que os pesquisadores e técnicos, ao absorverem e reproduzirem, sem crítica, as concepçōes estigmatizantes sobre as famílias pobres, acabam por oferecer argumentos e justificativas para as políticas especiais para a pobreza. Nesse diapasão, o enfoque jurídico, lato sensu, não considera que cada família "circula num modo particular de emocionar-se, que cria uma cultura familiar própria, com seus códigos, com uma sintaxe própria para comunicar-se e interpretar comunicaçóes, com suas regras, ritos e jogos" (Szymanski, 1995, p. 25). Ao contrário, exige uma adequação universalizada aos ditames do modelo monogâmico nuclear, burguês e patriarcal.

No entanto, esse "modelo ideal de família" não corresponde às possibilidades reais das famílias que vivem na pobreza, não somente do ponto de vista econômico-financeiro, mas, sobretudo, na pobreza de diversos fatores sociais e políticos. De um modo geral, as famílias não

Art. 226 e $\$ 3^{\circ}$ da Constituição de 1988. 
estão "desorganizadas", mas organizadas segundo necessidades que lhes são peculiares. Os processos que visam a normatizar as famílias segundo o que é considerado o normal, o adequado, estigmatizam e até mesmo violentam aquelas que fogem ao padrão.

Nessa perspectiva e com o objetivo de compreender como o ambiente judiciário se apresenta no panorama geral de desenvolvimento das famílias pobres, foi realizado esse trabalho de pesquisa, no qual uma das preocupaçóes era saber como o ambiente judiciário recepcionava e tratava esses grupos cujos conflitos estavam sendo processados.

\section{Método}

\section{$\mathrm{O}$ contexto pesquisado e os participantes}

A pesquisa foi realizada no ambiente judiciário, cuja descrição está para além do prédio do foro, salas de audiências, cartórios, locais por onde passam, todos os dias, milhares de pessoas em busca de respostas aos seus anseios. Portanto, além dos contextos físicos já expostos, a pesquisa se estendeu para as salas de espera da defensoria pública e assistência judiciária gratuita da Universidade. Foram foco deste estudo os balcões de atendimento das duas varas de famílias existentes na cidade. Mas o contexto físico por certo que não encerraria o que entendemos ser ambiente de influência na condução dos processos envolvendo conflitos familiares, podendo-se até mesmo afirmar que a trajetória dos profissionais representa contextos que influenciam no curso das "lides". Portanto, o trabalho utilizou-se da inserção ecológica (Cecconello \& Koller, 2004), metodologia que pressupóe a presença constante do pesquisador no ambiente a ser investigado, cujos procedimentos serão descritos a seguir.

\section{Procedimentos de coleta de dados}

A coleta de dados deu-se pela observação naturalística e construção de um diário de campo, onde foram anotadas as observaçôes feitas nos vários locais que compõem o ambiente judiciário conforme já exposto. Durante três meses, foram realizadas observações em audiências nas Varas de Família da Comarca Municipal, bem como nas salas de espera e balcóes de atendimento do Foro local. Foram também realizadas entrevistas semiestruturadas com os operadores do direito, eleitos a saber: um juiz de direito, um promotor de justiça, um defensor público e um assistente social, ora identificados respectivamente pelas letras "K", "X", "Y" e "Z"; bem como com os integrantes de uma família, cujo conflito se encontrava judicializado. Com relação a essa 
família, tratava-se de uma ação de alimentos ajuizada pela mãe contra o pai, para pleitear auxílio ao sustento dos seis filhos do casal. A entrevista com os profissionais foi realizada no ambiente de trabalho deles, e a entrevista com a família, na residência dos seus integrantes.

\section{A análise dos dados}

A análise dos dados seguiu os princípios dos modelos qualitativos. A análise textual discursiva (Moraes, 1999) eleita para orientar o trabalho consiste na unitarização, com posterior categorização e produção de interpretações pela leitura e escrita profunda em processos recursivos. Essa mesma orientação metodológica foi usada para análise e interpretação do diário de campo e das entrevistas. $\mathrm{Na}$ ocasião do projeto de pesquisa, o Comitê de Ética da Universidade Federal de Rio Grande não estava ainda constituído, e, por isso, as referidas propostas não foram apreciadas. Entretanto foram respeitadas todas as normas éticas de pesquisa com seres humanos previstas pelo Conselho Nacional de Saúde.

\section{Resultados}

Nesta sessão serão apresentadas as interpretações e reflexões sobre as principais dimensões que emergiram das análises das observações e das entrevistas realizadas no ambiente judiciário.

\section{a) A família na visão dos profissionais do Direito}

A investigação acerca da compreensão dos integrantes do ambiente judiciário acerca do tema família denotou que, embora os conceitos definidores de família fossem bastante abertos e abrissem espaço para as mais modernas concepções baseadas nas relações afetivas, os comportamentos dos profissionais entrevistados e suas atuações práticas conduziam para conclusões diversas. Entre todos os entrevistados, apenas um dos discursos apontava a família como organização, regras, estrutura:

Pra mim eu sempre entendi esta questão de família, né, homem e mulher se juntando, enfim, com interesse de prole. Aquela história das pessoas se relacionarem sem nenhum tipo de regramento, sempre deu uma confusão muito grande no momento de se estatuírem direitos, por isso houve uma necessidade de formação de família, com prole, descendência, ascendência e sucessão e direitos, que vieram... (X)

Enquanto que os demais apontavam a família como ambiente de afeto, convívio, cuidado: 
Neste contexto social, assim... é meio complicado definir família... É a gente com quem a gente conta. Família eu acho que é aquela que te oferece recursos afetivos, que promove o bem-estar de seus membros, que tem um papel decisivo na educação formal, informal, é o local onde se desenvolve a solidariedade, onde estamos transmitindo valores, eu acho que o que mais importa são os laços de solidariedade e afetividade (K).

Nesse contexto, os discursos sobre a família, na ótica dos profissionais atuantes na Justiça Familiar, parecem estar afinados com os tempos atuais, em consonância com as multifacetadas famílias contemporâneas e com os mais novos posicionamentos sobre o direito "das famílias" (Dias, 2005). Em sua recente obra, o pensador do Direito, Dias (2005, p. 32) declara:

A identidade familiar, apesar do que muitos dizem, não se mostra em decadência. Ao contrário, é o resultado das transformaçōes sociais. Houve a repersonalização das relações familiares na busca do atendimento aos interesses mais valiosos das pessoas humanas: afeto, solidariedade, lealdade, confiança, respeito e amor.

Tais afirmações são reiteradas por Ost (2005, p. 362), que alega:

É preciso render-se à evidência: de instituição garantindo a transmissão de patrimônios e garantindo a ordem simbólica dos lugares, a família transformou-se atualmente em uma 'rede de relações afetivas e de solidariedades', da qual o desafio é a construção de identidades pessoais nas trocas intersubjetivas.

No entanto, embora atuando na condução do conflito judicializado, os profissionais ainda expressam a ideia de que os conflitos familiares devem permanecer intramuros, não devendo ser discutidos perante outras pessoas: "Aquilo que, pra nós, que pra mim, por exemplo, eu acho que seria, ninguém tem que ficar sabendo, ninguém tem que ficar discutindo, não" $(\mathrm{Y})$.

O discurso deixa bastante claro que a imagem de família desse profissional é a da tradicional família nuclear burguesa, cujos problemas devem ser resolvidos no recesso do lar, longe dos olhares estranhos. E que tais problemas não devem ultrapassar os limites da casa para chegar ao conhecimento alheio, ou seja, os problemas devem ser escondidos, no afã de demonstrar a harmonia familiar que interessa à sociedade. Tal visão de família passou a coexistir em nossa sociedade, a partir do século XVII, desde quando começaram a aumentar as preocupações dos familiares e a expectativa social com relação à educação e cuidado das crianças (Ariés, 1981; Biasoli-Alves \& Sigolo, 1992; Macedo, 1994). Ariés (1981) afirma que a família moderna se reorganizou 
em torno da criança e ergue entre ela mesma e a sociedade o muro da vida privada, devido a uma "necessidade de intimidade". As famílias passaram a representar pequenas sociedades, distribuídas por classes. A família burguesa "retirou-se da vasta sociedade polimorfa para se organizar à parte, num meio homogêneo, entre suas famílias fechadas, em habitaçōes previstas para a intimidade, em bairros novos, protegidos contra toda contaminação popular” (Ariés, 1981, p. 279)

Ocorre que tal convicção, longe de demonstrar uma forma de manter a privacidade dos integrantes do grupo familiar, pode representar fator de risco para o desenvolvimento humano desse "núcleo" concebido como fechado. Sob a égide da privatização absoluta das relações e da manutenção do isolamento dos integrantes naquele núcleo, podem ser cometidos abusos entre os familiares, como os incontáveis casos de violência doméstica. As crenças dos profissionais que lidam com a proteção da família se operam de maneira efetiva na forma como conduzem a intervenção. Abusos podem ser desconsiderados por convicções do tipo: "filho tem que ficar com a mãe" ou "em briga de marido e mulher ninguém mete a colher".

Ao estabelecer o foco na estrutura e não na qualidade das inter-relaçóes familiares, os profissionais distanciam-se do problema e aceitam implicitamente os valores, as regras, as crenças e os padrōes emocionais do modelo nuclear. Dessa forma, lida-se com a família idealizada e não com a que está posta na vivência diária. Os componentes da família "vivida" (Szymanski, 1998) passam a idealizar suas relaçóes no modelo nuclear, aceitando a pecha de "incompletas" e "desestruturadas", o que gera sentimentos de incompetência entre os membros.

Toda essa estrutura de crenças conduz ao caminho inverso do que deveria ser percorrido. Os conflitos de interesses têm efeito para que ocorra a intervenção do Estado, no sentido de coibir abusos e gerar a efetiva proteção estatal, principalmente no que diz respeito à família. É um dos importantes fatores para a organização de uma sociedade equilibrada. Pensar nos interesses emocionais somente como algo isolado e próprio de cada indivíduo, fechado em seu casulo ou em seu pequeno grupamento familiar isolado da sociedade, representa um retrocesso, ainda mais quando se trata de famílias em situação de vulnerabilidade socioambiental. Ademais, importante ressaltar que o Estado, ao intervir nas relações de direito privado, o faz sempre com vistas à proteção não somente do indivíduo, mas fundamentalmente para atender aos interesses da coletividade. Por isso, as normas de direito de família, embora estejam inscritas no âmbito de direito privado, são entendidas como normas de interesse e ordem pública, "assim entendidas as regras que tutelam o interesse 
geral, atendendo mais o interesse da coletividade do que do indivíduo" (Dias, 2005, p. 32).

Cumpre frisar que as crenças e a postura dos profissionais que fazem parte da rede de apoio social apresentam-se como contextos ecológicos de influência das famílias (Bronfenbrenner, 1996). Estando ligados diretamente às políticas públicas de atendimento às populações em situação de risco, tais profissionais podem atuar como agentes mantenedores das desigualdades existentes ou como agentes potencializadores de mudança e de transformação da realidade das famílias atendidas.

Não bastassem essas conviç̧ões, a pobreza foi um fator apontado como um dos principais problemas na condução dos conflitos. Os profissionais se manifestaram da seguinte maneira:

Não sei se é porque aqui também a gente trabalha com pessoas de baixa renda, eu acho que os problemas surgem muito em função disso... Eu fico com essa visão porque eu estou acostumada a atender essas pessoas, um público em que um dos principais problemas é a falta de dinheiro $(\mathrm{Y})$.

Esse discurso mostra que as convicções dos profissionais são bastante preocupantes e seguem um modelo de discurso que aponta a pobreza como a raiz de grande parte dos problemas familiares. É como se, entre as camadas de maior poder aquisitivo, não houvesse conflitos nas famílias ou então ocorressem em escala menor. No entanto, a grande distinção existente entre essas populações e as populações pobres é que as últimas costumam ser atendidas pela rede pública, pelos serviços postos a sua disposição, independente de sua simpatia ou confiança na capacidade do profissional que não pode escolher, enquanto que as outras têm atendimento na esfera privada, por profissionais contratados segundo sua escolha e conveniência.

E não é outro o entendimento dos profissionais que, a despeito de culpabilizarem a situação financeira pelos conflitos, entendem que não há para as famílias em questão outra saída: "É diferente atuar com famílias de baixa renda, pois elas chegam ainda muito mais vulnerabilizadas" $(\mathrm{K})$.

Nesse sentido, a vulnerabilidade social atinge até mesmo a capacidade da busca pela rede de serviços. Feijó e Assis (2004), ao falarem do contexto da exclusão social, ressaltam os efeitos da segregação, que, ao privar o indivíduo de obter escolaridade, instrumento que representaria maiores chances de um emprego com melhor remuneração, assim como a possibilidade de acesso a informações que possa tornar efetivo o exercício de sua cidadania de forma plena. Aduzem as autoras mencionadas (2004) que a exclusão social é fator de 
classificação dos indivíduos como seres inferiores e diferentes, o que impede o usufruto pleno dos bens de consumo, da escola, de serviços de saúde, retirando-os convívio saudável e produtivo na comunidade. E, nesse sentido, os profissionais parecem não perceber que são esses aspectos macrossistêmicos que impõem à população pobre a vulnerabilidade da qual são vítimas:

É muito fácil, tu tá desempregado e aí tu não tem o que fazer, e o que se diz ainda o chefe de família, não é, então tá desempregado e então bebe, passa o dia bebendo, porque não tem emprego, porque não tem como trazer dinheiro para casa, e chega em casa e bate, enfim... Também não sei se foi isso que aumentou de lá pra cá e por isso eu tenho essa sensação de que esses conflitos pioraram ou que se tornaram mais intensos $(\mathrm{Y})$.

Não se pode prescindir do entendimento de que os conflitos familiares estão ligados a toda uma rede que implica envolvimentos dentro dos microssistemas, mas que são fundamentalmente influenciados por todos os outros sistemas nos quais os indivíduos estão inseridos, inclusive aqueles mais distantes (Bronfenbrenner, 1979/1996). Nesse sentido, existe o entendimento dos profissionais, ao menos no que diz respeito ao fato de que as dificuldades financeiras contribuem para a vulnerabilidade social: "Essas dificuldades todas assim, porque nós fazemos parte de um mundo essencialmente capitalista, onde realmente o Deus é o dinheiro, sem dinheiro não se consegue praticamente nada" $(\mathrm{X})$.

Os profissionais do Direito na visão das famílias

As famílias, por sua vez, se ressentem do fato de que suas relações restam extremamente prejudicada efeito, o desgastado discurso "só falo com você na presença do meu advogado" parece não ser parte somente das falas de novelas. As pessoas efetivamente bloqueiam o diálogo tão logo se estabeleça a relação "processual", que passa a vigorar com uma força incrivelmente opressora. As iniciativas de acertos consensuais parecem encontrar terreno tão somente no ambiente judiciário para dar "validade" aos diálogos. A chancela judicial toma uma proporção que vem demonstrar, mais uma vez, que a Justiça é vista pela população pobre como a própria lei, que não deve ser desobedecida em hipótese alguma e que, portanto, todo o diálogo deve obedecer ao rito do processo. A prática comum, todavia, era a "comunicação" somente ser estabelecida, se é que se pode falar em comunicação dentro da sala de audiências, principalmente entre as partes.

Para obter mais informações sobre as açóes, era mantido contato com as pessoas a respeito do motivo de sua presença no foro, e, na grande maioria dos 
diálogos estabelecidos, a fala mais comum era justamente esta: "Depois que a gente acionou a justiça, não conversamos mais" (fala com variáveis, mas com o mesmo sentido). Também com relação aos filhos, não era diferente: "Eu não vejo meus filhos há muito tempo, desde que a ação começou".

Pode-se creditar boa parte destas dificuldades como consequência das interações entre as famílias e os operadores do Direito. A falha existente na comunicação entre as pessoas e seus advogados, entre as "partes" e os juízes, e os promotores era evidente. Em geral, as pretensões não ficavam suficientemente claras aos profissionais, bem como as determinações, aconselhamentos, pareceres não eram sequer entendidos pelas famílias atendidas. A reação mais comum observada durante a inserção ecológica era o ar de estranhamento das pessoas ao saírem das salas de audiências. Era corriqueiro ouvir das partes as frases "Não entendi o que aconteceu lá dentro" ou "O que eu faço agora? Ficou ou não decidida a questão?"

Esse estranhamento foi uma das peças-chave para a efetiva compreensão da necessidade de mudanças no atendimento às pessoas. Com efeito, a eficácia do atendimento se perdia quando a comunicação falhava, e as falhas eram vistas diariamente, com frequência preocupante. Uma vez que a pretensão judicial é, em resumo, um "pedido" que as pessoas fazem ao Judiciário, como conceber que esse pedido seja feito se o interlocutor não compreende o que se quer? Por outro lado, como podem as pessoas estenderem seu pleitos à Justiça, quando não compreendem a linguagem, os significados que estão postos nesse ambiente? São perguntas que sinalizam a necessidade de colocar em alerta as políticas públicas de atendimento judiciário gratuito ou não, postas na atualidade à disposição das famílias pobres.

\section{Considerações finais}

Diante dos resultados apontados, pode-se perceber que as questões relativas às concepções sobre família na ótica dos profissionais ainda se ressentem de uma abordagem mais contemporânea que contemple a diversidade de configurações familiares no mundo atual. Tal fato transpareceu tanto nos discursos e condutas dos trabalhadores do Judiciário como na população atendida. As famílias são identificadas de forma "naturalizada" e na perspectiva tradicional nuclear burguesa. A naturalização das relaçóes familiares, que devem estar adequadas ao "modelo" a ser seguido, conduz a discursos normativos que acabam por influenciar não somente a maneira de direcionar os processos por parte dos profissionais, mas, sobretudo, influenciam a aceitação da população atendida. Esses fatores parecem representar interferências importantes na condução dos 
litígios. Uma vez que os conflitos não são elaborados de forma "saudável" por todos os atores envolvidos, poderão representar fatores a se somarem na sensação de incompetência das famílias e contribuírem para a manutenção das teorias que permeiam o imaginário social de desestruturação como causa de aumento dos conflitos familiares. Tratando-se de famílias pobres, as "teorias" referidas assumem um caráter ainda mais marcante, ao instante em que a pobreza é percebida por algumas categorias de agentes sociais como uma das grandes causadoras dos conflitos familiares (Yunes, 2001; Yunes, Garcia \& Albuquerque, 2007)

Por outro lado, as dificuldades de interação entre as partes conflitantes se devem, em alguma medida, às barreiras de comunicação existentes entre elas e os operadores do direito, seja pelas teorias implícitas acerca dos modelos idealizados de família, seja pelas dificuldades de comunicação entre as partes e os profissionais. Tais questóes representam verdadeiros fatores de risco na condução dos conflitos, principalmente se levarmos em conta a importância das intervenções estatais na promoção da saúde e bem-estar familiar.

\section{Referências}

Ariés, P. (1981). História social da criança e da família. Trad. Dora Flaksman. 2. ed. Rio de Janeiro: LTC.

Benincá, C. R. S. \& Gomes, W.B. (1998). Relatos de mães sobre transformações familiares em três geraçôes. Estudos de Psicologia, 3 (2), 177-205.

Biasoli-Alves, Z. M. M. \& Sigolo, S. R. R. L. (1992). Análise e categorização dos estudos sobre práticas de educação de crianças na família. Didática, 28, 103-114.

Bronfenbrenner, U. (1996). A ecologia do desenvolvimento humano: experimentos naturais e planejados. Porto Alegre: Artes Médicas. (Texto original publicado em 1979).

Cahali, Y. S. (2000). Divórcio e separação. São Paulo: Editora Revista dos Tribunais.

Carvalho, I. M. M. (2001). Brasil: reestruturação produtiva e condições sociais. Caderno $\mathrm{CRH}, 35,123-149$.

Carvalho, I. M.M. \& Almeida P. H. (2003). Família e proteção social. São Paulo Perspec., São Paulo, (17) 2. 
Carvalho, M. C. B. \& Guará, I. M. F. R. (1994). A família: um sujeito pouco refletido no movimento de luta pelos direitos da criança e do adolescente. Revista Brasileira de Crescimento e Desenvolvimento Humano, IV (1).

Cecconello, A. M. \& Koller, S. H. (2004). Inserção ecológica na comunidade: uma proposta metodológica para o estudo de famílias em situação de risco. In: S. H. Koller (org.). Ecologia do desenvolvimento humano: pesquisa e intervenção no Brasil. (pp. 267-292). São Paulo: Casa do Psicólogo.

Dias, M. B. (2005). Manual do direito das familias. Porto Alegre: Livraria do Advogado Editora.

Draibe, S. M. (1994). Por um reforço de proteção à família: contribuição à reforma dos programas de assistência social no Brasil. In: S. N. Kaloustina (org.). Familia brasileira, a base de tudo. (pp. 109-130). São Paulo: Cortez; Brasília: UNICEF.

Garcia, N. M. \& Yunes, M. A. M. (2006). Resiliência familiar: baixa renda e monoparentalidade. In: D. D. DellÁglio, S. H. Koller e M. A. M. Yunes (orgs.). Resiliência e Psicologia Positiva: Interfaces do Risco à Proteção. (pp. 117140). São Paulo: Casa do Psicólogo.

Goffman, E. (1988). Estigma: notas sobre a manipulação da identidade deteriorada. Rio de Janeiro: Guanabara.

Goldani, A. M. (2002). Las familias brasileñas y sus desafios como factor de protectión ao final do siglo XX. In: C. Gomes, (comp.). Procesos sociales, población y familia: alternativas teoricas y empiricas en las investigaciones sobre la vida domestica. (pp. 279-298). México: Miguel Angelo Porrua.

Gomes, J. V. (1992). Família e Socialização. Psicologia, Família e Educação, 3, 93-105.

Feijó, M. C. \& Assis, S. G. (2004). O contexto de exclusão social e de vulnerabilidade de jovens infratores e de suas famílias. Revista Estudos de Psicologia. Natal, 157-166.

Macedo, R. M. (1994). A família do ponto de vista psicológico: lugar seguro para crescer? Cadernos de Pesquisa, 91, 62-68.

Mello, S. L. (1995). Família: perspectiva teórica e observação factual. In: M. C. B. Carvalho (org.). A família contemporânea em debate. São Paulo: EDUC; Cortez. 
Montali, L. (2000). Família e trabalho na reestruturação produtiva: ausência de políticas de emprego e deterioração das condições de vida. Revista Brasileira de Ciências Sociais, 15 (42), 55-75.

Moraes, R. (1999). Análise de conteúdo. Educação, 37, 7-32.

Narvaz, M. G. (2005). Submissão e resistência: explodindo o discurso patriarcal da dominação feminina. Dissertação de Mestrado, Curso de Pós-graduação em Psicologia do Desenvolvimento, Universidade Federal do Rio Grande do Sul, Porto Alegre.

Oliveira, O. \& Ariza, M. (2002). Transiciones familiares y trayectoriaslaborales femininas en el Mexico urbano. In: C. Gomes (comp.). Procesos sociales, población y familia: alternativas teoricas y empiricas en las investigaciones sobre la vida domestica. (pp. 129-146). México: Miguel Angelo Porrua.

Ost, François. (2005). O tempo do direito. São Paulo: Edusc.

Rodrigo, M. J. \& Palacios, J. (1998). Família e desarrollo humano. Madrid: Alianza Editorial.

Rosemberg, F. (1994). Crianças pobres e família de risco: as armadilhas de um discurso. Revista Brasileira de Crescimento e Desenvolvimento Humano, IV, (1).

Salles, V. (2002). Familias en transformación y codigos por transformar. In: C. Gomes (comp.). Procesos sociales, población y familia: alternativas teoricas y empiricas en las investigaciones sobre la vida domestica. (pp. 103-125). México: Miguel Angelo Porrua.

Salles, V. (1999). Quando falamos de família, de que família estamos falando? Caderno CRH, 17, jul./dez., 106-140.

Sarti, C. A.(1996). A familia como espelho; um estudo sobre a moral dos pobres. Campinas: Editora Autores Associados.

Szymanski, H. (1995). Teoria e "teorias de famílias". In: M. C. B. Carvalho (org.). A família contemporânea em debate. (pp. 23-27). São Paulo: EDUC; Cortez.

Szymanski, H. (1998). Significados de família. In: Loch, G. M.; Yunes, M. A. M. (orgs.). A família que se pensa e a família que se vive. Rio Grande: Editora da FURG. 
Szymanski, H. (2004). Práticas educativas familiares: a família como foco de atenção psicoeducacional. Revista Estudos de Psicologia - PUC, Campinas, 21, (2), 5-16.

Tuiran, R. (2002). Estructura familiar y trayectorias de vida en Mexico. In: C. Gomes (comp.). Procesos sociales, población y familia: alternativas teoricas y empiricas en las investigaciones sobre la vida domestica. (pp. 25-65). México: Miguel Angelo Porrua.

Valadares, J. C. (1999). Espaço-ambiente e comportamento humano. In: L. E. Mello Filho et al.. (orgs.). Meio ambiente \& educação. (pp. 15-43). Rio de Janeiro: Griphus.

Valladares, L. P. (1991). Estudos recentes sobre habitação no Brasil: resenha de literatura. In: L. P. Valladares (org.). Repensando a habitação no Brasil. (p. 21-77). Rio de Janeiro: Zahar.

Yunes, M. A. M. (2001). A questão triplamente controvertida da resiliência em familias de baixa renda. Tese de Doutorado. Pontifícia Universidade Católica de São Paulo.

Yunes, M. A. M.; Miranda, A. T. \& Cuello, S. E. S. (2004). Um olhar ecológico para os riscos e as oportunidades de desenvolvimento de crianças e adolescentes institucionalizados. In: S. H. Koller (org.). Ecologia do desenvolvimento humano: pesquisa e intervenção no Brasil. (pp. 197-218). São Paulo: Casa do Psicólogo.

Yunes, M. A. M.; Garcia, N. M.; Albuquerque, B. de M. (2007). Monoparentalidade, pobreza \& resiliência: entre as crenças dos profissionais e as possibilidades da convivência familiar. Psicologia: Reflexão e Crítica, 20 (3), 444-453. 